\title{
Aortic stiffness as a predictor of high-sensitivity cardiac troponin T levels at a chronic stage after ST-segment elevation myocardial infarction
}

\author{
Hans-Josef Feistritzer ${ }^{1 *}$, Gert Klug ${ }^{1}$, Sebastian J Reinstadler ${ }^{1}$, Benjamin Seidner ${ }^{1}$, Johannes M Mair ${ }^{1}$, \\ Michael Schocke ${ }^{2}$, Wolfgang-Michael Franz ${ }^{1}$, Bernhard Metzler ${ }^{1}$
}

From 18th Annual SCMR Scientific Sessions

Nice, France. 4-7 February 2015

\section{Background}

Aortic stiffness is associated with early pulse wave reflection resulting in an increase of cardiac afterload and impairment of coronary perfusion. Experimental data show that high left ventricular pressure due to increased aortic stiffness is associated with enhanced myocardial cell death. We investigated whether aortic stiffness is related to high-sensitivity cardiac troponin $\mathrm{T}$ (hs-TnT) concentrations at a chronic stage 1 year after ST-segment elevation myocardial infarction (STEMI).

\section{Methods}

Seventy-four patients underwent cardiac magnetic resonance imaging for the assessment of left ventricular function, morphology, infarct size and aortic PWV 12 months after acute STEMI. Blood samples were drawn at 12 months by peripheral venipuncture. Hs-TnT levels were measured by a commercially available immunoassay (Roche Diagnostics ${ }^{\circledR}$ ).

\section{Results}

hs-TnT concentrations (6.4 ng/L, IQR 5.0 - 8.6) were significantly associated with age $(\mathrm{r}=0.417, \mathrm{p}<0.001)$, plasma creatinine levels $(r=0.257, p=0.027)$, high-sensitivityC-reactive protein levels $(\mathrm{r}=0.281, \mathrm{p}=0.015)$ and aortic PWV $(r=0.435, p<0.001)$. Multiple linear regression analysis revealed aortic PWV $(B=0.349, \mathrm{p}=0.014)$ beside, plasma creatinine concentrations $(\beta=0.288, \mathrm{p}=0.006)$ and diastolic blood pressure $(\beta=0.243, \mathrm{p}=0.015)$ to be independently associated with hs-TnT concentrations (model: $\mathrm{R}=0.622, \mathrm{p}<0.001$ ).

'University Clinic of Internal Medicine III, Cardiology and Angiology, Medical University of Innsbruck, Innsbruck, Austria

Full list of author information is available at the end of the article

\section{Conclusions}

Aortic stiffness is an indicator of prognosis after myocardial infarction. The present study suggests an impact of aortic stiffness on hs-TnT concentrations at 1 year after STEMI.

\section{Funding}

Austrian Society of Cardiology.

\section{Authors' details}

'University Clinic of Internal Medicine III, Cardiology and Angiology, Medical University of Innsbruck, Innsbruck, Austria. ${ }^{2}$ Departement of Radiology I, Medical University of Innsbruck, Innsbruck, Austria.

Published: 3 February 2015

doi:10.1186/1532-429X-17-S1-P127

Cite this article as: Feistritzer et al: Aortic stiffness as a predictor of high-sensitivity cardiac troponin T levels at a chronic stage after ST-segment elevation myocardial infarction. Journal of Cardiovascular Magnetic Resonance 2015 17(Suppl 1):P127.

Submit your next manuscript to BioMed Central and take full advantage of:

- Convenient online submission

- Thorough peer review

- No space constraints or color figure charges

- Immediate publication on acceptance

- Inclusion in PubMed, CAS, Scopus and Google Scholar

- Research which is freely available for redistribution 